\title{
VARIABILIDADE GENÉTICA DE ACESSOS DE PITAYA COM DIFERENTES NÍVEIS DE PRODUÇÃO POR MEIO DE MARCADORES RAPD ${ }^{1}$
}

\author{
KEIZE PEREIRA JUNQUEIRA², FÁBIO GELAPE FALEIRO³, GRACIELE BELLON ${ }^{3}$, \\ NILTON TADEU VILELA JUNQUEIRA ${ }^{3}$, KÊNIA GRACIELLE DA FONSECA ${ }^{3}$, \\ CRISTIANE ANDRÉA DE LIMA³, ERIVANDA CARVALHO DOS SANTOS ${ }^{3}$
}

RESUMO - A espécie de pitaya mais cultivada atualmente é Hylocereus undatus, a pitaya-vermelha-depolpa-branca. Colômbia e México são os principais produtores mundiais e, devido à sua rusticidade, a pitaya é considerada uma alternativa potencialmente viável também para o aproveitamento de solos pedregosos, arenosos e maciços rochosos. Apesar da crescente demanda, ainda não há uma cultivar lançada no mercado que atenda às necessidades climáticas de produção e às exigências do consumidor brasileiro. O presente trabalho é parte do programa de seleção e melhoramento da pitaya CPAC PY-01 da Embrapa Cerrados. Objetivou-se realizar o estudo da variabilidade genética de 16 acessos de pitayas mantidos na coleção de germoplasma da Embrapa Cerrados, apresentando diferentes características fenotípicas relacionadas especialmente à produção, por meio de marcadores moleculares RAPD (Random Amplified Polymorphic $D N A$ ). O DNA genômico de cada acesso foi extraído, e onze iniciadores decâmeros foram utilizados para a obtenção de marcadores moleculares RAPD, que foram convertidos em matriz de dados binários, a partir da qual foram estimadas as distâncias genéticas entre os acessos e realizadas análises de agrupamento e de dispersão gráfica. Foram obtidos 111 marcadores RAPD, perfazendo uma média de 10,1 marcadores por primer, dos quais $45(40,54 \%)$ foram polimórficos. As distâncias genéticas entre os 16 acessos variaram entre 0,006 e 0,148 . As maiores distâncias genéticas foram obtidas entre os acessos " 52 " e " 61 ", sendo que, em 2007, o primeiro produziu mais de 25 frutos, e o segundo, nenhum. Assim, deduz-se que, nesse caso, a próvável causa da variação seja genotípica. As menores distâncias genéticas foram constatadas entre os acessos "63"e "55" e entre "19"e "59". Os dois grupos apresentaram valores de produção próximos. Os marcadores moleculares RAPD mostraram que, mesmo dentro da mesma espécie, há variabilidade genética entre plantas com produções diferentes, ressaltando a importância das técnicas moleculares para subsidiar e auxiliar nos trabalhos de seleção, em programas de melhoramento genético.

Termos para indexação: marcadores moleculares, características agronômicas, Hylocereus undatus, melhoramento genético.

\section{PITAYA ACCESSES GENETIC VARIABILITY WITH DIFFERENT PRUDUCTION LEVELS THROUGH RAPD MARKERS}

\begin{abstract}
The most cultivated pitaya species nowadays is Hylocereus undatus, red pitaya with white pulp. Colombia and Mexico are the major world producers and, due to its rusticity, pitaya is considered a potentially viable alternative to make good use of gravel, sandy and compact rocky soils. Although the great demand, there is not yet a variety released on the market that attends production climatic needs and Brazilian consumer exigencies. The present work is a part of Embrapa Cerrados pitaya CPAC PY-01 selection and improvement program. It has had the objective to realize genetic variability study of 16 pitaya accesses maintained at Embrapa Cerrados germoplasm collection, showing different phenotypic characteristics with special relation to production, through molecular markers RAPD (Random Amplified Polymorphic DNA). The genomic DNA of each access was extracted and eleven decamer primers indicators were used to obtain molecular markers RAPD that were converted in a binarium data matrix, from where it was estimated genetic distances between accesses and realized grouping analysis and graphic dispersion. One hundred and eleven RAPD markers were obtained, making a 10, 1 markers medium per primer, in which $45(40,54 \%)$ were polymorphic. Genetic distances between 16 accesses varied within 0,006 and 0,148 . The biggest genetic distances were obtained between accesses " 52 " and " 61 "; in 2007, the first one produced more than 25 fruits and the second one, none. The smallest genetic distances were verified between accesses " 63 " and " 55 " and between 19" and "59". Both groups showed close production values. RAPD molecular markers showed that, even inside the same species, there is genetic variability between plants with different productions, standing out molecular techniques importance as auxiliary instruments selection in breeding programs.
\end{abstract}

Index terms: molecular markers, agronomic characteristics, Hylocereus undatus, breeding program.

${ }^{1}$ (Trabalho 186-09). Recebido em: 10-08-2009. Aceito para publicação em: 02-03-2010. Apoio financeiro: CAPES e Embrapa Cerrados.
${ }^{2}$ Embrapa Transferência de Tecnologia, Embrapa Sede, Parque Estação Biológica - PqEB s/nº, 70770-901, Brasília, DF. E-mail: keize.
junqueira@embrapa.br
${ }^{3}$ Embrapa Cerrados, BR 020, Km 18, C.P. 08223, 73010-970 Planaltina-DF. E- mail: ffaleiro@cpac.embrapa.br, junqueir@cpac.embrapa.br 


\section{INTRODUÇÃO}

Pertencentes à família Cactacea, as pitayas vêm destacando-se no mercado de frutas exóticas. Há várias espécies denominadas "pitayas", dentre as quais podem ser citadas Hylocereus undatus (pitaya-vermelha-de-polpa-branca), Hylocereus costaricensis (pitaya-vermelha-de-polpa-vermelha), Selenicereus megalanthus (pitaya-amarela) e Selenicereus setaceus (pitaya-do-cerrado). Há também outras espécies de ocorrência em áreas de Cerrado (JUNQUEIRA et al., 2007) e acredita-se que o Brasil seja um dos centros de origens das pitayas.

A espécie mais cultivada atualmente é a pitaya-vermelha-de-polpa-branca. Os frutos são bastante atrativos, de coloração vermelha e polpa esbranquiçada, com numerosas sementes pretas. Segundo Ortiz e Liveira (1995), a pitaya-vermelha possui alto potencial agronômico e econômico. De acordo com Junqueira et al. (2002), devido à sua rusticidade, a pitaya é considerada uma opção também para o cultivo em solos pedregosos, arenosos e maciços rochosos.

Os preços atualmente cotados nos mercados regional, nacional ou internacional têm estimulado a extensão e a intensificação do cultivo da pitaya em diferentes sistemas de plantio, no México, Nicarágua, Malásia, Vietnã e Israel (HESEN;TELLEZ, 1995; NERD;MIZRAHI, 1997; RODRÍGUEZ, 2000, citados por ANDRADE et al., 2007). No Brasil, existem pequenas áreas de produção de pitaya, situadas principalmente no Estado de São Paulo, localizadas na região de Catanduva. Na região Sudeste, a produção dos frutos ocorre durante os meses de dezembro a maio. A produtividade média anual é de 14 toneladas de fruto/ha (BASTOS et al., 2006).

Entretanto, ainda não há uma cultivar lançada que, além de atender às necessidades climáticas de produção, satisfaça também às exigências do consumidor. As mudas comercializadas atualmente não são provenientes de sementes selecionadas e observa-se, num mesmo plantio, grande variação na produção, tamanho e formato de frutos, bem como em suas características físico-químicas, refletindo a desuniformidade das mudas e necessidade de existência de uma cultivar indicada para a região.

O presente trabalho é parte do programa de seleção e melhoramento da pitaya CPAC PY-01 da Embrapa Cerrados. Neste programa, acessos têm sido avaliados e selecionados com base, principalmente, em características físicas e químicas de frutos e produtividade. Para o sucesso do trabalho de seleção na obtenção de ganhos genéticos, é essencial que exista variabilidade genética entre os diferentes acessos. Neste sentido, objetivou-se realizar o estudo da variabilidade genética de 16 acessos de pitayas mantidos na coleção de germoplasma da Embrapa Cerrados, apresentando diferentes características fenotípicas relacionadas especialmente à produção, por meio de marcadores moleculares RAPD (Random Amplified Polymorphic DNA).

\section{MATERIAL E MÉTODOS}

O trabalho foi realizado no Laboratório de Genética e Biologia Molecular da Embrapa Cerrados. Foram analisados 16 acessos de pitaya-vermelha-depolpa-branca (Hylocereus undatus), com dois anos de idade, pertencentes à Coleção de Germoplasma da Embrapa Cerrados (Tabela 1). Cladódios em estágio inicial de maturação foram coletados, e o DNA genômico extraído, utilizando-se do método do CTAB, com algumas modificações (FALEIRO et al., 2003).

Amostras de DNA de cada material genético foram amplificadas para a obtenção de marcadores RAPD. As reações de amplificação foram feitas em um volume total de $13 \mu \mathrm{L}$, contendo Tris- $\mathrm{HCl} 10$ $\mathrm{mM}$ (pH 8,3), $\mathrm{KCl} 50 \mathrm{mM}, \mathrm{MgCl}^{2} 3 \mathrm{mM}, 100 \mu \mathrm{M}$ de cada um dos desoxirribonucleotídios (dATP, dTTP, dGTP e dCTP), $0,4 \mu \mathrm{M}$ de um iniciador (Operon Technologies Inc., Alameda, CA, EUA), uma unidade da enzima Taq polimerase e, aproximadamente, $15 \mathrm{ng}$ de DNA. Foram utilizados 11 iniciadores decâmeros: OPD (01; 02; 05 e 11), OPE (11), OPF (08 e 14), OPG (18) e OPH $(04 ; 13$ e 15) (Tabela 2$)$.

As amplificações foram efetuadas em termociclador programado para 40 ciclos, cada um constituído pela seguinte sequência: 15 segundos a $94^{\circ} \mathrm{C}, 30$ segundos a $35^{\circ} \mathrm{C}$ e 90 segundos a $72^{\circ} \mathrm{C}$. Após os 40 ciclos, foi feita uma etapa de extensão final de seis minutos a $72^{\circ} \mathrm{C}$ e, finalmente, a temperatura foi reduzida para $4{ }^{\circ} \mathrm{C}$. Após a amplificação, foram adicionados, a cada amostra, $3 \mu \mathrm{l}$ de uma mistura de azul de bromofenol $(0,25 \%)$ e glicerol $(60 \%)$, em água. Essas amostras foram aplicadas em gel de agarose $(1,2 \%)$, corado com brometo de etídio, submerso em tampão TBE (Tris-Borato $90 \mathrm{mM}$, EDTA $1 \mathrm{mM})$. A separação eletroforética foi de, aproximadamente, quatro horas, a 90 volts. Ao término da corrida, os géis foram fotografados sob luz ultravioleta.

Os marcadores RAPD gerados foram convertidos em matriz de dados binários, a partir da qual foram estimadas as distâncias genéticas entre os diferentes acessos, com base no complemento do coeficiente de similaridade de Nei e Li (1979), utilizando-se do Programa Genes (CRUZ, 1997). 
A matriz de distâncias genéticas foi utilizada para realizar análises de agrupamento por meio de dendrograma, utilizando-se do método do UPGMA (Unweighted pair-group arithmetic average) como critério de agrupamento, e a dispersão gráfica, baseada em escalas multidimensionais, usando o método das coordenadas principais, com auxílio do Programa SAS (SAS INSTITUTE INC., 1989) e Statistica (STATSOFT INC., 1999).

\section{RESULTADOS E DISCUSSÃO}

Os marcadores RAPD mostraram-se excelentes ferramentas para detectar a variabilidade genética em pitayas, fato já observado por Junqueira et al. (2007), em trabalhos com acessos de pitayas nativos. Os 11 primers decâmeros geraram um total de 111 marcadores RAPD, perfazendo uma média de 10,1 marcadores por primer. Dos 111 marcadores, 45 (40,54\%) foram polimórficos (Tabela 2). A baixa porcentagem de marcadores polimórficos evidencia a baixa variabilidade genética dos acessos analisados. Tal resultado já era esperado, tendo em vista que se trata da mesma espécie e que os acessos já se encontram em fase avançada de seleção, estreitandose a base genética da população analisada.

As distâncias genéticas entre os 16 acessos de pitaya variaram entre 0,006 e 0,148 (Tabela 3). As maiores distâncias genéticas foram obtidas entre os acessos " 52 " e "61". Considerando que, em 2007, o primeiro produziu mais de 25 frutos, e o segundo, nenhum, deduz-se que, neste caso, a próvável causa da variação seja genotípica. As menores distâncias genéticas foram constatadas entre os acessos " 63 "e " 55 " e entre "19"e " 59 ". Nos dois casos, observaramse valores de produção próximos. Junqueira et al. (2007), estudando acessos nativos de pitaya, de diferentes espécies, obtiveram distâncias variando entre 0,088 e 0,848 , comprovando a larga base genética das pitayas de modo geral e concluíndo ser o Brasil um dos maiores centros de diversidade dessas frutas.

Com base na análise de agrupamento realizada a partir das distâncias genéticas, subdividiram-se os 16 acessos em, pelo menos, quatro grupos de similaridade genética (Figura 1). O maior grupo foi formado por 10 dos 16 acessos. Dentro deste grupo, pode-se verificar significativo agrupamento das plantas mais produtivas. Os frutos de diferentes formatos não formaram grupos específicos. Outro grupo foi formado apenas pelo acesso " 52 ", que produziu mais de 25 frutos na referida safra. $\mathrm{O}$ terceiro grupo foi constituído pelos acessos " 19 ", "59", "26" e "1", sendo que os três últimos não produziram frutos na safra de 2007. O último grupo foi formado pelo acesso " 61 ”, que não produziu frutos em 2007, porém apresentou alto vigor.

O perfil de agrupamento também pode ser constatado no gráfico de dipersão (Figura 2), onde se evidencia a diferença do acesso " 61 " em relação aos demais e a tendência de agrupamento dos acessos com base em sua produtividade verificada, parcialmente, na análise de agrupamento. Considerando que os acessos analisados possuem a mesma base genética, ou seja, foram originados de uma mesma população, possivelmente diferentes grupos de genes estão condicionando maior ou menor produtividade, abrindo boas perspectivas para os trabalhos de seleção e melhoramento genético. 
TABELA 1 - Acessos de pitaya analisados.

\begin{tabular}{|c|c|c|}
\hline Número & Acesso & Características agronômicas \\
\hline 1 & Planta "51" & Produção de mais de 25 frutos na safra de 2007; frutos “ovoides". \\
\hline 2 & Planta “ $52 "$ & Produção de mais de 25 frutos na safra de 2007; frutos “ovoides". \\
\hline 3 & Planta “ $53 "$ & Produção de mais de 25 frutos na safra de 2007; frutos "ovoides". \\
\hline 4 & Planta “ $55 "$ & Produção de mais de 25 frutos na safra de 2007; frutos “ovoides". \\
\hline 5 & Planta “47” & Produção entre 15 e 25 frutos na safra de 2007; frutos "ovoides". \\
\hline 6 & Planta “63” & Produção entre 15 e 25 frutos na safra de 2007; frutos "ovoides". \\
\hline 7 & Planta “28”, & Produção entre 15 e 25 frutos na safra de 2007; frutos "longos". \\
\hline 8 & Planta "33" & Produção entre 15 e 25 frutos na safra de 2007; frutos "longos". \\
\hline 9 & Planta “4” & Produção entre 1 e 15 frutos na safra de 2007; frutos "ovoides". \\
\hline 10 & Planta "13" & Produção entre 1 e 15 frutos na safra de 2007; frutos "ovoides". \\
\hline 11 & Planta “22” & Produção entre 1 e 15 frutos na safra de 2007; frutos "ovoides". \\
\hline 12 & Planta “19” & Produção entre 1 e 15 frutos na safra de 2007; frutos "longos". \\
\hline 13 & Planta “59”, & Não produziu frutos na safra de 2007; planta com alto vigor vegetativo. \\
\hline 14 & Planta “61”, & Não produziu frutos na safra de 2007; planta com alto vigor vegetativo. \\
\hline 15 & Planta “ $1 "$ & Não produziu frutos na safra de 2007; planta com baixo vigor vegetativo. \\
\hline 16 & Planta “26" & $\begin{array}{l}\text { Não produziu frutos na safra de 2007; planta com baixo vigor vegetativo } \\
\text { e notável suscetibilidade à antracnose. }\end{array}$ \\
\hline
\end{tabular}

TABELA 2 - Iniciadores utilizados para a obtenção dos marcadores RAPD e respectivos números de bandas polimórficas e monomórficas.

\begin{tabular}{cccc}
\hline Iniciador & Sequência 5 $^{\prime}{ }^{\circledR} \mathbf{3}^{\prime}$ & $\mathbf{N}^{\mathbf{0}}$ de bandas polimórficas & $\mathbf{N}^{\mathbf{0}}$ de bandas monomórficas \\
\hline OPD-1 & ACCGCGAAGG & 3 & 3 \\
OPD-2 & GGACCCAACC & 2 & 6 \\
OPD-5 & TGAGCGGACA & 3 & 4 \\
OPD-11 & AGCGCCATTG & 2 & 10 \\
OPE-2 & GGTGCGGGAA & 5 & 11 \\
OPF-8 & GGGATATCGG & 6 & 7 \\
OPG-5 & CTGAGACGGA & 3 & 6 \\
OPH-2 & TCGGACGTGA & 3 & 5 \\
OPH-4 & GGAAGTCGCC & 3 & 4 \\
OPH-13 & GACGCCACAC & 1 & 8 \\
OPH-15 & AATGGCGCAG & 14 & 2 \\
\hline
\end{tabular}


TABELA 3-Matriz de distâncias entre 16 acessos de pitaya, baseada em 111 marcadores RAPD.

\begin{tabular}{|c|c|c|c|c|c|c|c|c|c|c|c|c|c|c|c|}
\hline & 1 & 2 & 3 & 4 & 5 & 6 & 7 & 8 & 9 & 10 & 11 & 12 & 13 & 14 & 15 \\
\hline 1 & - & & & & & & & & & & & & & & \\
\hline 2 & 0,047 & - & & & & & & & & & & & & & \\
\hline 3 & 0,041 & 0,060 & - & & & & & & & & & & & & \\
\hline 4 & 0,030 & 0,034 & 0,029 & - & & & & & & & & & & & \\
\hline 5 & 0,037 & 0,062 & 0,034 & 0,029 & - & & & & & & & & & & \\
\hline 6 & 0,018 & 0,038 & 0,039 & 0,006 & 0,034 & - & & & & & & & & & \\
\hline 7 & 0,030 & 0,050 & 0,051 & 0,024 & 0,030 & 0,023 & - & & & & & & & & \\
\hline 8 & 0,018 & 0,061 & 0,051 & 0,023 & 0,047 & 0,017 & 0,029 & - & & & & & & & \\
\hline 9 & 0,038 & 0,069 & 0,047 & 0,048 & 0,036 & 0,035 & 0,036 & 0,030 & - & & & & & & \\
\hline 10 & 0,041 & 0,054 & 0,033 & 0,017 & 0,034 & 0,022 & 0,029 & 0,034 & 0,040 & - & & & & & \\
\hline 11 & 0,043 & 0,088 & 0,048 & 0,061 & 0,025 & 0,059 & 0,055 & 0,061 & 0,031 & 0,041 & - & & & & \\
\hline 12 & 0,031 & 0,081 & 0,071 & 0,048 & 0,067 & 0,047 & 0,054 & 0,024 & 0,056 & 0,053 & 0,043 & - & & & \\
\hline 13 & 0,036 & 0,068 & 0,064 & 0,029 & 0,048 & 0,035 & 0,041 & 0,029 & 0,062 & 0,052 & 0,049 & 0,006 & - & & \\
\hline 14 & 0,120 & 0,148 & 0,120 & 0,113 & 0,107 & 0,110 & 0,104 & 0,125 & 0,121 & 0,114 & 0,108 & 0,114 & 0,104 & - & \\
\hline 15 & 0,068 & 0,109 & 0,101 & 0,071 & 0,091 & 0,082 & 0,091 & 0,065 & 0,093 & 0,088 & 0,074 & 0,037 & 0,042 & 0,139 & - \\
\hline 16 & 0,032 & 0,090 & 0,074 & 0,055 & 0,057 & 0,055 & 0,063 & 0,050 & 0,070 & 0,055 & 0,026 & 0,026 & 0,031 & 0,1320 & 0,051 \\
\hline
\end{tabular}

* O número do acesso é o mesmo da Tabela 1.

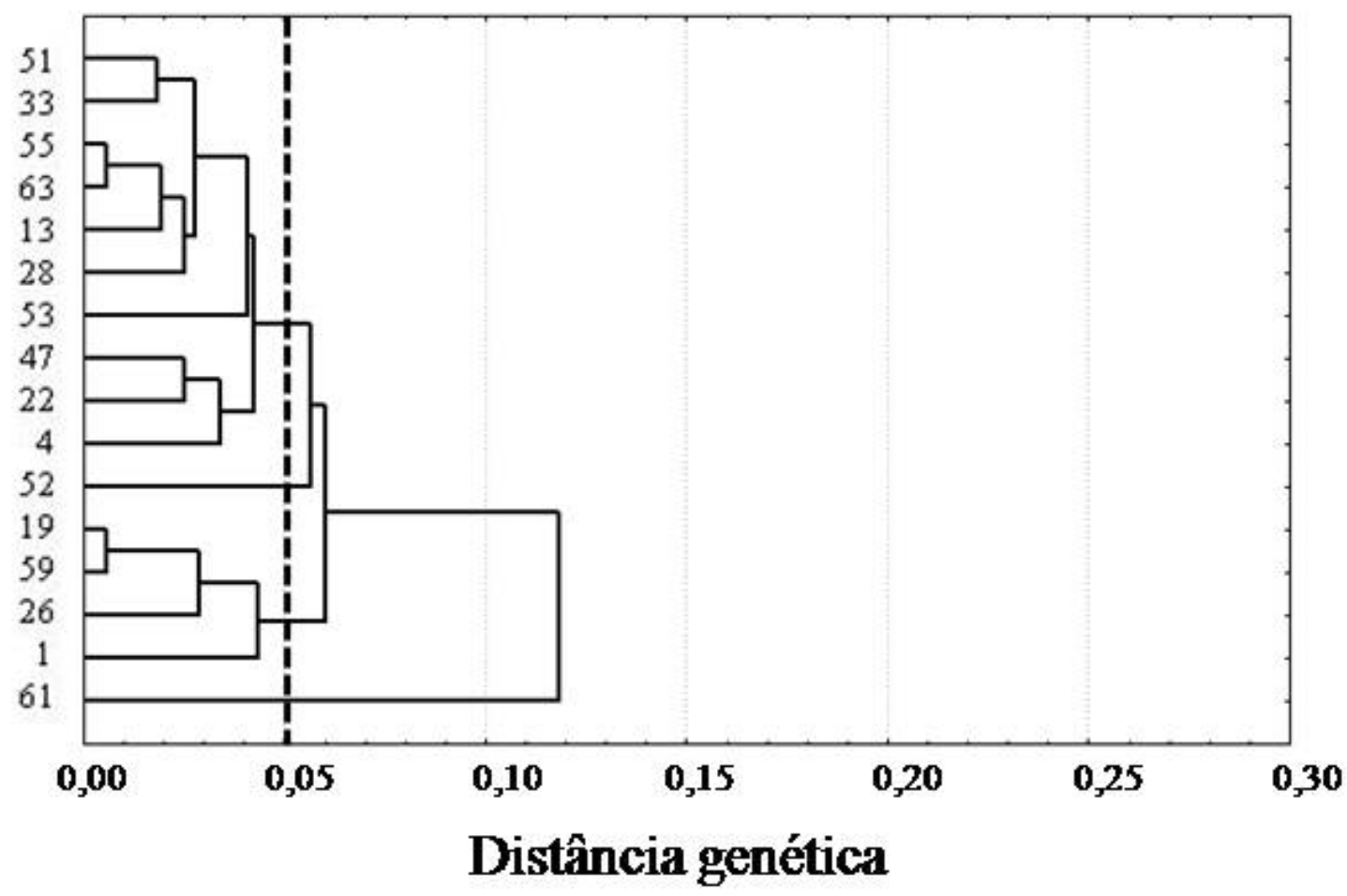

FIGURA 1- Análise de agrupamento de 16 acessos de pitaya com base na matriz de distâncias genéticas calculadas, utilizando-se de 111 marcadores RAPD. O método do UPGMA foi utilizado como critério de agrupamento. 


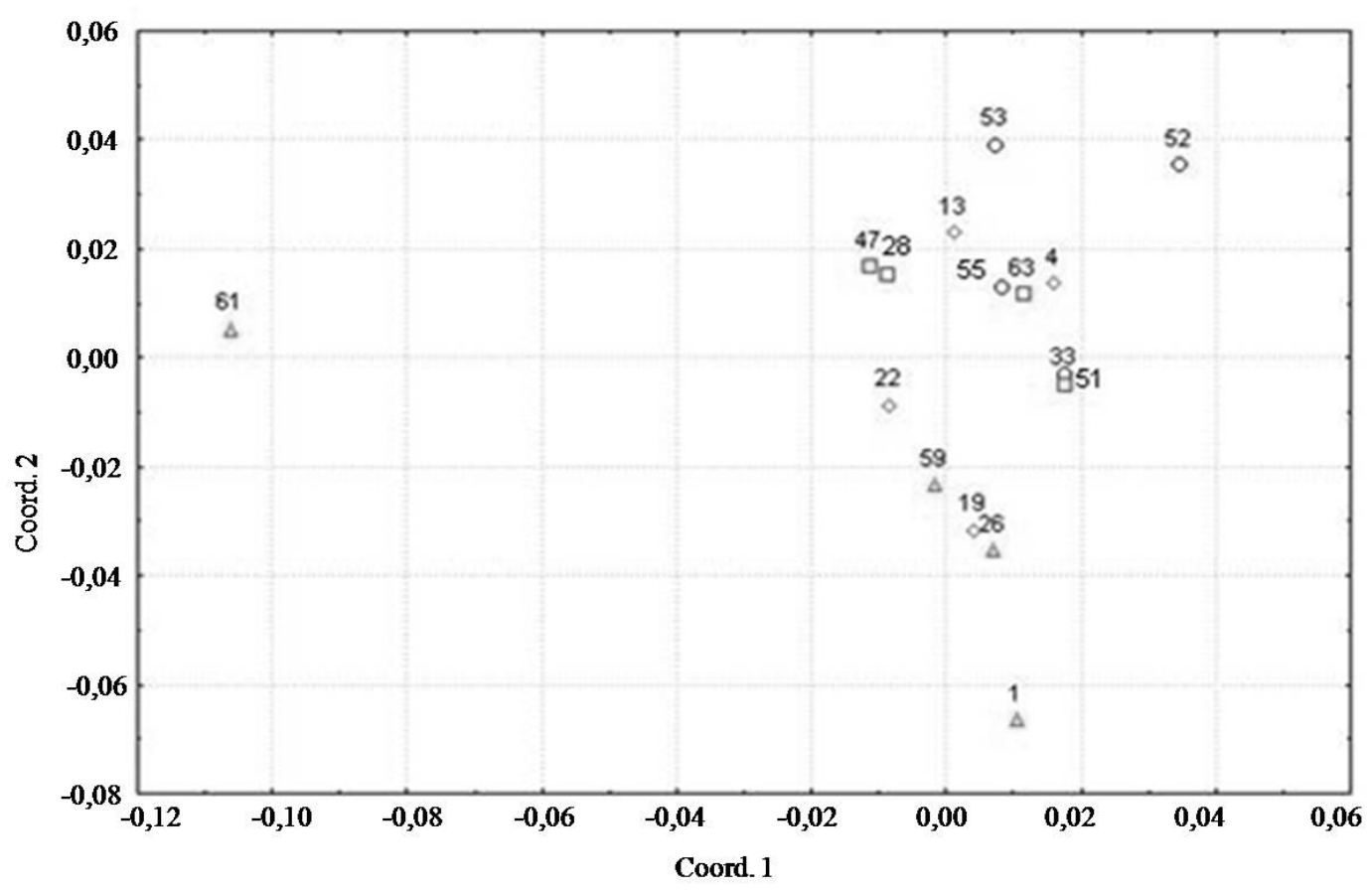

FIGURA 2- Dispersão gráfica de 16 acessos de pitaya com base na matriz de distâncias genéticas calculadas, utilizando-se de 111 marcadores RAPD. Os números correspondem aos acessos da Tabela 1, sendo acessos com produção de mais de 25 frutos (o); entre 15 e 25 frutos ( $\square$ ); entre 1 e 15 frutos $(0)$ e sem produção $(\Delta)$.

\section{CONCLUSÕES}

A partir de marcadores moleculares RAPD, constata-se que, dentro da mesma espécie, há variabilidade genética entre plantas com produções diferentes, ressaltando a importância das técnicas moleculares para subsidiar e auxiliar os trabalhos de seleção em programas de melhoramento genético de pitaya. Tal fato vai subsidiar futuros trabalhos de avaliação agronômica e seleção desses acessos, principalmente objetivando o lançamento de uma cultivar de pitaya no mercado.

\section{REFERÊNCIAS}

ANDRADE, R.A.; MARTINS, A. B.G.; SILVA, M.T.H. Influência da fonte material e do tempo de cura na propagação vegetativa da pitaya-vermelha (Hylocereus undatus Haw). Revista Brasileira de Fruticultura, Jaboticabal, v.29, n.1, p.183-186, 2007.
BASTOS, D.C.; PIO, R.; SCARPARE FILHO, J.A.; LIBARDI, M.N.; ALMEIDA, L.F.P.; GALUCHI, T.P.D.; BAKKER, S.T. Propagação da Pitaya'vermelha' por estaquia. Ciência e Agrotecnologia, Lavras, v.30, n.6, p.1106-1109, 2006.

CRUZ, C.D. Programa Genes: aplicativo computacional em genética e estatística. Viçosa: UFV, 1997. 442p.

FALEIRO, F.G.; FALEIRO, A.S.G.; CORDEIRO, M.C.R.; KARIA, C.T. Metodologia para operacionalizar a extração de DNA de espécies nativas do cerrado. Planaltina: Embrapa Cerrados, 2003. 6 p. (Comunicado Técnico, 92).

JUNQUEIRA, K. P. ; FALEIRO, F. G.; JUNQUEIRA, N.T.V.; BELLON, G. ; FONSECA, K.G.; LIMA, C.A.; SANO, S.M . Diversidade genética de Pitayas nativas do cerrado com base em marcadores RAPD. In: CONGRESSO BRASILEIRO DE MELHORAMENTO DE PLANTAS, 4., 2007, São Lourenço. Anais... 
JUNQUEIRA, K.P.; JUNQUEIRA, N.T.V.; RAMOS, J.D.; PEREIRA, A.V. Informações preliminares sobre uma espécie de pitaya do Cerrado. Planaltina-DF: Embrapa Cerrados, 2002. 18p. (Documentos, 62).

NEI, M.; LI, W. H. Mathematical model for studying genetic variation in terms of restriction endonucleases. Proceedings of the National Academy of Science of the United States of America, Washington, v.76, n. 10, p. 5269-5273, 1979.
ORTIZ, H.Y.D.; LIVERA, M.M. La pitahaya (Hylocereus spp): Recurso genético de América. In: CONGRESO NACIONAL, 6 Y INTERNACIONAL SOBRE EL CONOCIMIENTO Y APROVECHAMIENTO DEL NOPAL, 4. 1995. Guadalajara. Memórias... p.191-194.

SAS INSTITUTE. SAS/STAT: user's guide. Version 6, $4^{\text {th }}$ ed. North Caroline, 1989.

STATSOFT. Statistica for windows: computer program manual. Tulsa, 1999. 